\title{
UMA ANÁLISE DE INTERLÍNGUAS EM APRENDIZES BRASILEIROS DE ESPANHOL: A INTERFERÊNCIA DO INFINITIVO (FLEXIONADO) NA ESCRITA DE SUBORDINADAS FINAIS
}

Cristiane Caroline Moreira Gomes

Orientadora: Profa. Dra. Rozana Reigota Naves

RESUMO: Este artigo apresenta os resultados do estudo de produções escritas por estudantes brasileiros de Espanhol, isto é, professores aprendizes de um projeto do Centro Interescolar de Línguas de Brazlândia (CILB) no DF. Busca-se aqui observar estágios de interlíngua na aquisição de Espanhol como L2 pelo uso do infinitivo (flexionado) em construções finais, ou seja, em períodos compostos por orações subordinadas adverbiais finais. A pesquisa deu-se através de um trabalho de análise de entrevistas/questionários, de planos de aula e de avaliações (provas) desenvolvidos pelos próprios sujeitos, bem como de e-mails trocados com os mesmos na língua-alvo. A Teoria Gerativa e teorias de aquisição de $L 1$ e $L 2$ orientam e convergem com o desenvolvimento e com as conclusões deste trabalho: há diferentes estágios de interlíngua na aquisição do Parâmetro da Flexão do Infinitivo em orações finais por falantes de Português aprendizes de Espanhol e há interferência e transferência de valores paramétricos da L1 (Português) no processo da aquisição de Espanhol L2.

PALAVRAS-CHAVE: Espanhol como L2, aquisição de L2, marcas do Português, interlíngua, infinitivo flexionado, orações finais.

ABSTRACT: This academic work presents the study's results of the writing by brazilian apprentices teachers of Spanish from a project of the Centro Interescolar de Línguas de Brazlândia (CILB) in the Federal District. We want to observe interlanguage stages in the acquisition of Spanish as L2 by the use of the (inflected) infinitive to express purpose, it means, in complex sentences with adverbial clauses of purpose. The research was done through a work of analysis of interviews, 
questionnaires, lesson plans and assessments (tests) developed by the subjects themselves, as well as emails exchanged with them in the target language. The Generative Theory and the theories of the acquisition of $L 1$ and $L 2$ guide and converge with the development and conclusions of this work: there are different interlanguage stages in the acquisition of the Infinitive Flexion Parameter in clauses of purpose by Portuguese speakers who learn Spanish and there is interference and transfer of L1 (Portuguese) parametric values in the process of acquisition of Spanish L2.

KEY-WORDS: Spanish as L2, acquisition of L2, traces of Portuguese, interlanguage, inflected infinitive, clauses of purpose.

\section{Introdução}

Os períodos compostos por orações subordinadas parecem constituir-se um aprendizado mais complexo tanto em L1 como em L2. Ao pormenorizar as construções oracionais que são formuladas na língua portuguesa em uso a partir de conjunções subordinativas adverbiais, Neves (2000) descreve não menos que dez classes, sendo elas: as construções temporais, as causais, as condicionais, as concessivas, as finais, as comparativas, as consecutivas, as conformativas, as proporcionais e as modais.

Neste trabalho, em especial, examinam-se desvios na formulação, por brasileiros, de construções finais em Espanhol L2, fenômeno popularmente batizado de "portunhol". Isto porque é comum encontrar a interferência e mesmo a fossilização de estruturas típicas do Português, tanto na oralidade, como na produção escrita de aprendizes brasileiros de Espanhol L2, mesmo após anos de aprendizagem/aquisição e de ensino da referida L2. A apresentação de marcas do Português como o uso do infinitivo flexionado nas construções finais - em detrimento do uso do infinitivo não flexionado ou do uso do presente do subjuntivo ${ }^{1}-$ é um exemplo dos desvios estudados nesta pesquisa.

${ }^{1}$ Os referidos usos são aclarados na próxima seção deste trabalho. 
Dessa forma, partindo do arcabouço gerativista, objetiva-se neste trabalho formalizar a constatação de tais desvios - quanto à interferência do Parâmetro da Flexão do Infinitivo em orações subordinadas finais - e explorar os processos que envolvam a construção de orações subordinadas finais no Espanhol L2. Para tal, analisaram-se dados de amostras coletadas na produção escrita por professores aprendizes de Espanhol do Centro Interescolar de Línguas de Brazlândia (CILB), escola pública do Distrito Federal (DF) na qual os próprios sujeitos pesquisados estud(ar)am previamente Espanhol como L2. ${ }^{2}$

Importa ressaltar que na literatura especializada não há muitos métodos e/ou trabalhos que discutam amplamente o tema do infinitivo (flexionado) na interlíngua do aprendiz brasileiro de Espanhol. Busca-se aqui, portanto, fomentar tal discussão, visando estimular o desenvolvimento de futuros trabalhos mais aprofundados sobre o tema e que envolvam outras construções no âmbito de interlíngua, como contextos diversos de usos do infinitivo, do futuro do subjuntivo, além das orações temporais. Assim, esta pesquisa defende a hipótese da transferência de valores paramétricos da L1 durante a aquisição da L2 a partir da concepção de interlíngua, conforme conceituado na seção 3 deste artigo.

\section{Comparando a forma das orações finais nas línguas portuguesa e espanhola}

\section{(1) a. Ele deve estudar este caso PARA chegar a uma conclusão. b. PARA chegar a uma conclusão, ele deve estudar este caso. Construção final/Oração principal/Oração final}

$\mathrm{Na}$ língua portuguesa, as construções finais podem formar-se através de orações encabeçadas, por exemplo: pela locução conjuntiva PARA QUE ou pela preposição PARA, como em (2); pela locução conjuntiva A FIM DE QUE ou pela lo-

2 No CILB, desenvolve-se o projeto "Professor Aprendiz" em que (ex-)alunos com desempenho sobressaliente e interesse pelo ensino de idiomas dão aulas à comunidade de Brazlândia como professores aprendizes no período noturno. 
cução prepositiva A FIM DE, como apontado em (3). Em ambos os exemplos, constituem-se períodos compostos (cf. NEVES, 2000, pp. 884-885).

(2) a. PARA QUE eles cheguem/chegassem a uma conclusão, nós devemos/devíamos apresentar uma defesa.

b. PARA eles chegarem a uma conclusão, nós devemos apresentar uma defesa.

(3) a. A FIM DE QUE eles cheguem/chegassem a uma conclusão, nós devemos/devíamos apresentar uma defesa.

b. A FIM DE eles chegarem a uma conclusão, nós devemos apresentar uma defesa.

c. A FIM DE chegar(em) a uma conclusão, eles devem estudar o caso.

Neves (2000, pp. 886-887) destaca que orações finais conjuntivas (como as introduzidas por PARA QUE e A FIM DE QUE) são construídas com o presente ou o pretérito imperfeito do subjuntivo, além de apresentarem obrigatoriamente sujeito diferente do sujeito da oração principal, como em (2a) e (3a). Já as orações finais prepositivas (como as introduzidas por PARA e A FIM DE) apresentam infinitivo não flexionado ou flexionado - em concordância com o sujeito desta oração (3c) e sujeito da oração final diferente do sujeito da oração principal, como em (2b) e (3b), ou sujeito da oração final correferencial ao do da oração principal, como em (1a), (1b) e (3c).

Quanto à língua espanhola, Castro $(1999,2008)$ aponta que as orações finais podem ser encabeçadas por PARA (QUE), CON EL FIN DE (QUE), entre outros. Se os sujeitos da oração final e o da principal diferem, a oração final é obrigatoriamente conjuntiva, constituindo-se com o presente ou o pretérito imperfeito do subjuntivo (4a). Orações finais prepositivas são introduzidas por infinitivo e só podem compôrse caso os sujeitos da oração final e da principal sejam correferenciais (4b).

(4) a. PARA QUE (ellos) lleguen/llegaran-llegasen a la conclusión, (nosotros) debemos/deberíamos presentar defensa. 
b. PARA [él] llegar a la conclusión, (él) debe estudiar el caso.

$\mathrm{Na}$ língua espanhola, dentre outras características, o infinitivo, enquanto forma verbal não pessoal: (i) pode apresentar complementos, como em (5a); e (ii) admite pronomes enclíticos, como em (5b) (cf. MORENO \& FERNÁNDEZ, 2007, p. 298).

(5) a. "Es bueno tener amigos."

(MORENO \& FERNÁNDEZ, 2007, p. 298)

b. "Debemos contárselo."

(MORENO \& FERNÁNDEZ, 2007, p. 298)

Moreno \& Fernández (2007, p. 298) mostram inclusive que, funcionando como substantivo, o infinitivo aceita flexão de número, como em (6). Entretanto, assumindo sua função primeira de verbo, o infinitivo não apresenta flexões para além dos três grupos de terminações que admite nessa língua, conforme apresentado no quadro 1 .

(6) "el deber/los deberes, el poder/los poderes, el amanecer/los amaneceres".

Quadro 1 - Formação do infinitivo na língua espanhola

\begin{tabular}{|c|c|c|c|}
\hline \multirow{2}{*}{ Infinitivo } & C. & RAÍZ & TERMINACIONES \\
\cline { 2 - 4 } & $1^{\mathrm{a}}$ & Am- & -ar \\
\hline $2^{\mathrm{a}}$ & Tem- & -er \\
\hline & $3^{\mathrm{a}}$ & Part- & -ir \\
\hline
\end{tabular}

(SÁNCHEZ; MARTíN; MATILLA, 1997, p. 81)

Isso é, diferentemente do Português (veja-se quadro 2), na língua espanhola, não há marcas de pessoalidade na formação do infinitivo enquanto verbo. 
Quadro 2 - Formação do infinitivo flexionado na língua portuguesa (nossa autoria)

\begin{tabular}{|c|c|c|c|c|c|c|c|}
\hline \multirow{2}{*}{ Infinitivo } & \multicolumn{4}{c|}{ Flexões do infinitivo } \\
\cline { 2 - 8 } & \multicolumn{3}{c|}{ SINGULAR } & \multicolumn{3}{c|}{ PLURAL } \\
\hline \multirow{2}{*}{ CONJUGAÇÃO } & RAIZ E & $1^{a}$ & $2^{a}$ & $3^{a}$ & $1^{a}$ & $2^{a}$ & $3^{a}$ \\
& TERMINAÇÃO & pes. & pes. & pes. & pes. & pes. & pes. \\
\hline $1^{a}$ & Amar & - & $-e s$ & - & -mos & -des & -em \\
\hline $2^{a}$ & Temer & - & $-e s$ & - & -mos & -des & -em \\
\hline $3^{a}$ & Partir & - & -es & - & -mos & -des & -em \\
\hline
\end{tabular}

Sendo assim, neste artigo, busca-se analisar construções de períodos compostos por subordinações adverbiais finais por professores aprendizes (brasileiros) de Espanhol como L2 do Centro Interescolar de Línguas de Brazlândia (CILB), observando a interferência (ou não) de uma interlíngua em suas produções escritas.

\section{Referencial teórico-metodológigo}

Há décadas os estudos gerativistas têm abarcado pesquisas que envolvem o fenômeno de aquisição da linguagem, bem como estudos que tratam da compreensão de processos linguísticos que permeiam a aquisição de segunda língua (e concomitantemente processos referentes ao bilinguismo).

Em 1957, Noam Chomsky publica Syntactic Structures, contestando a corrente de pensamento do Estruturalismo - em especial as concepções referentes ao conhecimento linguístico. Chomsky, de vertente racionalista, defende que a fonte da aprendizagem nasce de processos mentais (para além de experiências e estímulos externos). Assim, o pai da teoria gerativa postula a hipótese da Faculdade da Linguagem como uma capacidade humana inata para adquirir línguas. Defende, consequentemente, que a criança já é dotada de uma Gramática Universal (GU), constituída de princípios linguísticos de origem genética, natural e autônoma e que a capacitam a adquirir qualquer língua - por mais que receba estímulos linguísticos primários empobrecidos, o ser humano é capaz de produzir sentenças complexas de 
uma língua natural. Não somos capazes de falar ou escrever apenas o que ouvimos ou lemos previamente.

Ainda sobre o conceito de Gramática Universal, Xavier \& Morato (2014, p. 18) esclarecem que é "um conjunto das propriedades gramaticais compartilhadas por todas as línguas naturais", e, sobre as diferenças entre as línguas, "que são previsíveis segundo as diversas opções disponíveis na própria GU”. Os linguistas também adicionam que "[...] a linguagem seria um órgão mental, que agiria de forma independente apesar de ter ligações com outras interfaces”.

Dando continuidade aos estudos da GU, Chomsky postula, em 1981, a Teoria dos Princípios e Parâmetros (P\&P): os princípios da GU dizem respeito a uma gramática inata, nuclear, invariante e universal (ou seja, princípios intrínsecos a todas as línguas humanas) e os parâmetros correspondem às possibilidades de variações das línguas adquiridas e fixadas através das experiências de aquisição de uma/s determinada/s língua/s natural/is.

Logo, os P\&P nos permitem observar as diferenças e semelhanças entre todas as línguas naturais, corroborando para a proposta de uma GU. Por exemplo, se os sujeitos das orações que constituem uma construção final são diferentes (não correferenciais), no Português do Brasil (PB) aceita-se que o verbo da oração final apareça em subjuntivo ou infinitivo flexionado (7). Já no Espanhol, admite-se apenas o uso do subjuntivo (8), sendo o infinitivo (não flexionado) usado somente quando, nesses tipos de orações, os sujeitos são correferenciais (9). Vê-se, então, a marcação de um parâmetro no $\mathrm{PB}$, aqui intitulado de Parâmetro da Flexão do Infinitivo. ${ }^{3}$

(7) a. Isto aconteceu para que mudemos nossas atitudes.

b. Isto aconteceu para mudarmos nossas atitudes.

(8) a. Ello ha pasado para que cambiemos nuestra actitud..

b. *Ello ha pasado para cambiarmos nuestra actitud.

${ }^{3} \mathrm{O} / \mathrm{s}$ asterisco/s nos exemplos deste artigo indicam que a/s sentença/s é/são agramatical/is. 
(9) Pasamos por un mal momento para cambiar nuestra actitud.

Sobre os P\&P, Souza (2014, p. 67) em alusão a Flynn (1998) acrescenta:

[...] ainda que a teoria da GU, em sua formulação pelos linguistas gerativistas, não faça afirmações diretas sobre processos bilíngues, uma parte da comunidade de pesquisadores em aquisição de segunda língua (em especial nos EUA e na Europa) viu-se inclinada a conceber que, se a teoria de Princípios e Parâmetros alçava o construto da GU ao patamar de caracterizador do processo de aquisição da linguagem humana, então seria razoável supor que tal construto fizesse também referência aos processos de aquisição de L2. Um aspecto preponderante dos estudos que se alinharam a essa perspectiva foi a busca de evidências empíricas que respondessem ao questionamento geral sobre serem as interlínguas configuradas como gramáticas restritas por princípios e parâmetros universais, ou não.

O conceito de interlíngua, por sua vez, foi postulado por Selinker (apud Yokota, 2001, pp.18-19), para quem a aprendizagem de uma L2 por falantes não nativos (como adultos) está vinculada a estruturas latentes (linguística e psicológica). A estrutura psicológica latente está relacionada a fenômenos como a transferência linguística de conhecimentos prévios e a hipergeneralização de regras em contextos desnecessários/não permitidos. Outro conceito importante em Selinker é o da fossilização, ou seja, mesmo após um suposto domínio de estruturas linguísticas específicas - e a depender da situação comunicativa em que o falante não nativo se encontre -, desvios continuam a aparecer. A interlíngua pode ser entendida, então, como uma língua do falante não nativo e/ou do aprendiz de L2 que, entretanto, difere-se da L1 e da L2.

Ainda segundo Souza (2014, p. 70), algumas perspectivas defendem que "há, no estado inicial da aquisição de $L 2$, a transferência também de projeções funcionais da L1 e dos valores paramétricos para elas fixados". E, além disso, apresenta-se, conforme o modelo proposto por Schwartz \& Sprouse (1996) de plena transferência/pleno acesso à GU (full transfer/full access), que "o aprendiz de L2 organizará o insumo da língua alvo integralmente a partir da gramática parametrizada que já foi adquirida." Entretanto, De Freitas Júnior (2014, pp.141-142) em alusão à White (1993) propõe que "se considerarmos que, se os aprendizes 
somente são capazes de adotar os princípios e parâmetros da $L 1$, isso indicaria que o suposto acesso à GU seria parcial, ou mesmo nulo". Assim como o acesso à GU poderia ser total ou parcial, há linhas de estudo que defendem a hipótese de transferência parcial da gramática da L1 (partial transfer), a qual parece corresponder com os resultados desta pesquisa.

Logo, a partir dos referidos pressupostos apresentados, neste trabalho, busca-se compreender a aquisição do Espanhol como L2 a partir da análise de orações finais construídas por nativos do PB (L1). Os dados analisados foram coletados no período de 10 de março de 2017 a 29 de maio de 2017 a partir de emails trocados com os professores aprendizes do projeto noturno do Centro Interescolar de Línguas de Brazlândia (CILB), escola pública do DF especializada no ensino de idiomas (atualmente Espanhol, Francês e Inglês). Os e-mails diziam respeito a planos de aula e avaliações (provas) desenvolvidos pelos próprios professores aprendizes. Os referidos professores aprendizes são 3 sujeitos -2 do sexo feminino e 1 do sexo masculino - na faixa etária de 18 a 20 anos (para garantir a privacidade dos sujeitos, não indicam-se seus nomes): a primeira professora aprendiz começou a dar aulas no projeto noturno do CILB neste semestre e ainda cursa o último nível do curso diurno de Espanhol da mesma escola (iniciado há 3 anos), além disso é recém-ingressa no curso de Biblioteconomia de uma instituição federal em Brasília; a segunda estudou por 7 anos no curso regular de Espanhol do CILB (ex-aluna), cursa Bacharelado em Línguas Estrangeiras Aplicadas (LEA) em uma instituição federal de Brasília e agora dá aulas como professora aprendiz no projeto noturno anteriormente mencionado; o último professor aprendiz desse projeto noturno do CILB também é ex-aluno do curso diurno de Espanhol da escola em questão e cursa licenciatura em Letras Espanhol em outra instituição federal de Brasília, além de haver tido experiência de aprendizado em um país de língua espanhola durante 1 mês - deste, infelizmente, conseguimos analisar o menor quantitativo de amostras.

Os sujeitos foram divididos em 2 grupos: 1) concluindo o nível B1 do Quadro Europeu Comum de Referência para Línguas (QECR); 2) possuindo nível B2 ou superior no QECR. 
Aplicaram-se os seguintes instrumentos de coleta de dados: a) entrevistas conversacionais com os sujeitos; b) questionários de identificação dos sujeitos; c) coleta e examinação de produção textual em língua espanhola pelos sujeitos para a análise linguística (não houve necessidade de eliciação dessas produções, já que fazia parte do trabalho dos sujeitos a produção dos referidos materiais, de forma que as amostras apresentadas são plenamente autênticas).

A coleta de dados (via e-mails trocados) propôs-se a observar a hipótese de interferência da L1 na aquisição de L2 relacionada aos parâmetros preestabelecidos da L1, considerando diferentes níveis de interlíngua ao analisar a produção escrita em língua espanhola por brasileiros, professores aprendizes de Espanhol.

\section{Análise de dados}

Nesta seção do artigo, dispõe-se a etapa de análise dos dados coletados em um total de 20 textos garimpados dos sujeitos (sendo 10 textos do sujeito do Grupo "1" e 10 textos dos sujeitos do Grupo "2", conforme grupos descritos na seção anterior deste trabalho).

Para a análise dos dados coletados, procurou-se observar: (i) a ocorrência, nas produções escritas, de construções/orações finais que respeitassem os parâmetros da língua padrão espanhola e (ii) a ocorrência, nas produções escritas, de estruturas que mais se aproximassem da L1 (PB) no que concerne às construções finais.

Visando-se uma ampla compreensão da análise, transcrevem-se a seguir exemplos de construções finais escritas pelos sujeitos da pesquisa:

(9)Sujeitos correferenciais:

a. [...]tienen dos minutos /para escribir todas las palabras que puedan sobre todo lo necesario para pasar unos días en la playa. (Sujeito 1, Plano de aula 1 - Grupo 1) 
b. Para practicar las formas de imperativo afirmativo y negativo,/ van a completar la tabla del ejercicio 5 de la página 73[...] (Sujeito 1, Plano de aula 1 - Grupo 1)

c. En el cuadro de Comunicación se presentan estructuras/ para expresar síntomas de una enfermedad y remedios. (Sujeito 1, Avaliação 1 - Grupo 1)

d. Para presentar personas,/ podemos hablar de sus gustos, profesión, familia etc. (Sujeito 1, Plano de aula 1 - Grupo 1)

e. Para ir a Plaza de Castilla/ tengo que hacer[...]. (Sujeito 1, Avaliação 2 - Grupo 1)

f. ¿Por qué no van a tener problemas/ para encontrar alojamiento? (Sujeito 1, Avaliação 2 - Grupo 1)

g. Para afianzar la pronunciación,/ recordaremos la entonación interrogativa. (Sujeito 1, Plano de aula 2 - Grupo 1)

h. Para practicar,/ los alumnos harán el ejercicio [...] (Sujeito 1, Plano de aula 2 Grupo 1)

i. Para repasar el vocabulario, con los libros cerrados,/ van a escribir todos los adjetivos [...]. (Sujeito 1, Plano de aula 2 - Grupo 1)

j. ¿Hay algo que podamos hacer/ para arreglar el problema del agua? (Sujeito 1, Email 1 - Grupo 2)

k. Harán una serie de actividades en fotocopias/ para entrenar la gramática. (Sujeito 2, Plano de aula 1 - Grupo 2)

I. [...] la persona puede hacer preguntas/ para adivinar la profesión [...] (Sujeito 1, Plano de aula 2 - Grupo 2)

m. [...] ellos tienen que tomar algunas notas esquemáticas, basándose en las preguntas,/ para conversar con el compañero. (Sujeito 1, Plano de aula 2 - Grupo 2) 
n. [...] ellos van a completar las frases de la actividad 7,/ para formar frases condicionales. (Sujeito 1, Plano de aula 3 - Grupo 2)

o. [...] después ellos van a ir a la pizarra/ para escribir las sílabas tónicas y la tilde de cada frase [...] (Sujeito 1, Plano de aula 3 - Grupo 2)

(10)Sujeitos não correferenciais:

a. *Poner la grabación/ para ellos señalaren en el dibujo los consejos que oigan. (Sujeito 1, Plano de aula 1 - Grupo 1)

b. [...] * ¿qué es mejor: [yo] dar[le] la frase/ para la persona completar, como su sugerencia o para marcar? (Sujeito 1, Email 3 - Grupo 2)

c. Anotar en la pizarra la solución/ para que nadie se equivoque. (Sujeito 1, Plano de aula 1 - Grupo 1)

d. Luego, poner la escucha/ para que hagan los ejercicios que se [les] proponen. (Sujeito 1, Plano de aula 2 - Grupo 1)

e. Poner en el slide las reglas de los comparativos/ para que los alumnos [las] copien. (Sujeito 1, Plano de aula 1 - Grupo 2)

f. [...] escribir en la pizarra algunos pares/ para que [los alumnos] hagan [las] comparaciones. (Sujeito 1, Plano de aula 1 - Grupo 2)

g. Cada alumno va a escoger un artista y dar pistas sobre el artista/ para que los compañeros puedan adivinar [quién es el artista]. (Sujeito 1, Plano de aula 5 Grupo 2)

(11) Sujeitos correferenciais (ou não?):

a. Para terminar, /pedir que ellos digan más palabras relacionadas con cada deporte. (Sujeito 1, Plano de aula 4-Grupo 2) 
b. Escribir[,] en nueve papeles, nombres distintos de profesiones/ para que podamos poner[los] en la frente de las personas. (Sujeito 1, Plano de aula 2 Grupo 2)

(12) Infinitivo com admissão/omissão de pronome enclítico:

a. [...] aclarando que la usamos/ para referirnos a las personas [...con las que] nos llevamos bien. (Sujeito 1, Plano de aula 2 - Grupo 1)

b. [...] leer las preguntas de la actividad 4, /para después contestarlas. (Sujeito 1, Plano de aula 2 - Grupo 2)

c. [...] voy a poner las palabras pronunciadas equivocadamente en la pizarra/ para que podamos repetir[las] correctamente [...] (Sujeito 1, Plano de aula 1 - Grupo 2)

d. Buscar intentos en otras actividades o métodos distintos/ para permitir[le] al alumno un aprendizaje dinámico del vocabulario. (Sujeito 2, Plano de aula 1 Grupo 2)

e. [...] dispondrán de un rato de tiempo/ para indicar[le] al profesor el nombre de los objetos [...] (Sujeito 2, Plano de aula 1 - Grupo 2)

(13) Uso de PARA no lugar de QUE e omissão do subjuntivo:

a. *Pedirlos/ para escribir un pequeño párrafo sobre con las cosas que les interesa [...] (Sujeito 1, Plano de aula 2 - Grupo 1)

b. *Pedir voluntarios/ para leer la tabla de pronunciación y ortografía [...] (Sujeito 1, Plano de aula 2 - Grupo 1)

(14) Uso de PARA no lugar de EN, DE e $\varnothing$, respectivamente:

a. *Como han comprado mucha cosa ahora tienen dificultad para guardar todo. (Sujeito 1, Avaliação 3 - Grupo 1) 
b. [...] *el reportaje que has leído puede ser una buena oportunidad para encontrar empleo [...] (Sujeito 1, Avaliação 4 - Grupo 1)

c. [...] ¿¿Qué necesitarás para llevar? (Sujeito 1, Avaliação 2 - Grupo 1)

De acordo com a análise, os dados observados em (9) nos permitem afirmar que, provavelmente, todos os sujeitos (dos grupos 1 e 2) têm fixado o parâmetro de não flexão do infinitivo em orações finais em Espanhol com sujeitos correferenciais.

Quanto à interferência do Parâmetro da Flexão do Infinitivo (PB-L1) em construções com sujeitos não correferenciais (Espanhol-L2), pode-se constatar que o sujeito 1 do Grupo 1 (concluindo o nível B1 do QECR) apresenta uma fase de (re)fixação de parâmetros na referida $L 2$, já que em (10a) há interferência desse parâmetro em sua produção escrita, porém em (10c) e (10d) fez-se uso adequado do presente do subjuntivo.

Nenhum dos sujeitos do Grupo 2 (que possuem nível B2 ou superior no QECR) demonstrou interferência do Parâmetro da Flexão do Infinitivo (PB-L1) em suas produções escritas em Espanhol. Entretanto, o sujeito 1 do Grupo 2 mostrou em (10b) a interferência no uso do infinitivo não flexionado em orações finais com sujeitos não correferenciais em Espanhol, ainda que em (10e), (10f), (10g), (11a), (11b) e (12c) tenha mostrado domínio no uso do subjuntivo.

Interessantemente, observou-se que em (10b), (11b), (12c), (12d) e (12e) os sujeitos do Grupo 2 omitiram o uso de pronomes junto aos verbos em infinitivo das orações finais, o que poderia indicar uma super/hipergeneralização no uso do infinitivo não flexionado - já que o infinitivo, enquanto forma verbal não pessoal (que não se flexiona), admite, porém, pronomes enclíticos em Espanhol. O sujeito 1 do Grupo 1 (com nível de proficiência menor conforme o QECR), por sua vez, usou pronomes enclíticos junto ao infinitivo, como em (12a) e ainda que em (13a) tenha usado o pronome "los" no lugar de "les"- fenômeno conhecido como loísmo e encontrado mesmo entre falantes nativos -, mostra que entende o infinitivo como forma verbal que admite pronomes enclíticos em Espanhol. 
Portanto, os fatos expostos nos últimos parágrafos voltam-se às hipóteses de estágios de interlíngua e transferência de parâmetros apresentadas no referencial teórico-metodológico deste trabalho, pois apontam que, entre a L1 e a L2, existe um sistema latente de transferência de parâmetros que reflete no desempenho dos aprendizes em sua expressão escrita de orações finais.

Uma última questão é que o sujeito 1 do Grupo 1 apresentou outros usos claramente típicos da L1 como em (13) e (14). Tais usos não se propunham apresentar neste trabalho, mas foram aqui listados por chamarem a atenção, já que envolvem o uso da preposição PARA - tipicamente usada em construções finais, as quais nos propúnhamos a analisar em primeira instância neste artigo.

\section{Conclusões}

Foi trazida, neste trabalho, uma proposta de análise sobre a aquisição de propriedades estruturais do Espanhol por brasileiros (PB-L1) - especificamente o emprego do infinitivo (flexionado) versus o presente do subjuntivo - a partir da análise de situações concretas de produção escrita de orações subordinadas finais.

Esta pesquisa, que se baseia na concepção de estágios de interlíngua, estabelece relações quanto ao Parâmetro da Flexão do Infinitivo em Português e em Espanhol para orações finais tendo-se constatado que os sujeitos pesquisados (brasileiros, professores aprendizes de Espanhol como L2) apresentam interferências dos parâmetros de sua L1 na produção escrita de orações finais.

Os sujeitos desta pesquisa demonstraram, ora produções com um nível mais próximo da língua-alvo (ao utilizar verbos no presente do subjuntivo em orações finais com sujeitos não correferenciais), ora estágios intermediários de interlíngua (ao utilizar verbos em infinitivo flexionado), por exemplo. Ou seja, marcas do Português (sua L1) ainda foram encontradas em sua produção escrita em Espanhol L2. 
Importa esclarecer que, mesmo considerando que os dados analisados foram obtidos de e-mails, os corretores automáticos não foram capazes de assimilar, por exemplo, o Parâmetro da Flexão do Infinitivo no lugar do subjuntivo quando os sujeitos das orações finais em Espanhol são correferenciais.

Desse modo, a partir da análise dos dados comparativos dos grupos em questão, é possível afirmar que:

(i) há diferentes estágios de interlíngua na aquisição do Parâmetro da Flexão do Infinitivo em orações finais por falantes de Português aprendizes de Espanhol;

(ii) há interferência e transferência de valores paramétricos da L1 (Português) no processo da aquisição de Espanhol L2.

Sabe-se que a discussão sobre os limites da competência em L2 é um tema recorrente nos estudos linguísticos. Souza (2014, p. 66), apresenta um panorama dos estudos de aquisição de segunda língua e bilinguismo que comprova essa questão:

\footnotetext{
Nemser (1971) refere-se à representação da L2 manifesta por um aprendiz de L2 como um sistema aproximativo, conceptualizado como dinâmico, pois tem a possibilidade de distanciamento progressivo dos padrões da $\mathrm{L} 1 \mathrm{e}$ concomitante convergência com os padrões da L2. Porém, a formulação explícita de um sistema relativamente autônomo em relação à sua L1 e aos modelos da L2 que o aprendiz recebeu, para o qual foi proposta a designação de interlíngua, se dá em Selinker (1972).
}

Assim, pontua-se novamente a necessidade da continuidade de estudos com viés gerativista que se aprofundem na abordagem da aquisição do Espanhol como L2 e do bilinguismo Português-Espanhol, de forma a contribuir futuramente com o desenvolvimento de propostas de "aprendizagem e ensino escolar" de êxito em Espanhol no Brasil.

\section{Referências}


CASTRO, Francisca. Uso de la gramática española: Gramática y ejercicios de sistematización para estudiantes de E.L.E de nivel avanzado. $2^{\mathrm{a}}$ ed. Espanha: Edelsa, 1999. 138 pp.

CASTRO, Francisca. Uso de la gramática española: Gramática y ejercicios de sistematización para estudiantes de E.L.E de nivel intermedio. 16 ed. España: Edelsa, 2008. 163 pp.

DE FREITAS JÚNIOR, Roberto. Revisitando conceitos de aquisição de L2: Defendendo propostas teóricas abrangentes. In: Pensares em Revista. São Gonçalo (RJ): jan./jul. 2014, n. 4, pp. 135 -157. Disponível em: <www.epublicacoes_teste.uerj.br/index.php/pensaresemrevista/article/view/14118/11478> Acesso em: 24 julho de 2017.

LIMA, Marisa Dias; NAVES, Rozana Reigota. Aquisição do Português escrito por surdos: uma investigação da relação com a de aquisição de Língua de Sinais Brasileira. Disponível em:</lebooks.pucrs.br/edipucrs/anais/sial/2011/src/37.pdf>. Acesso em: junho de 2017.

MORENO, Concha; FERNÁNDEZ, Gretel Eres. Gramática contrastiva del español para brasileños. $1^{\text {a }}$ ed. Madri: SGEL, 2007. 374 pp.

NEVES, Maria Helena de Moura. Gramática de usos do português. São Paulo: Editora UNESP, 2000. 1037 pp.

SÁNCHEZ, Aquilino; MARTíN, Ernesto; MATILLA, J.A. Gramática práctica de español para extranjeros. $17^{\mathrm{a}} \mathrm{ed}$. Madri: SGEL,1997. $231 \mathrm{pp}$.

SOUZA, Ricardo A. Gerativa: (inter)faces de uma teoria - Capítulo 3. $1^{\text {a }}$ ed. Florianópolis (SC): Beconn, 2014. 184 pp.

XAVIER, Gláucia do Carmo; MORATO, Rodrigo A. Gerativa: (inter)faces de uma teoria - Capítulo 1. $1^{\text {a }}$ ed. Florianópolis (SC): Beconn, 2014. 184 pp.

YOKOTA, Rosa. A marcação de caso acusativo na interlíngua de brasileiros que estudam o espanhol. 2001. Tese de Doutorado. Universidade de São Paulo. 
Disponível em: <http://www.teses.usp.br/teses/disponiveis/8/8139/tde-19042002214712/pt-br.php> Acesso em: julho de 2017. 